\title{
Pyruvate kinase M2 phosphorylates H2AX and promotes genomic instability in human tumor cells
}

\author{
Li Xia ${ }^{1}$, Kang Qin ${ }^{1}$, Xin-Ran Wang ${ }^{1}$, Xiao-Ling Wang ${ }^{1}$, Ai-Wu Zhou ${ }^{1}$, Guo-Qiang Chen ${ }^{1}$ \\ and Ying Lu ${ }^{1}$ \\ ${ }^{1}$ Department of Pathophysiology, Key Laboratory of Cell Differentiation and Apoptosis of Ministry of Education, Shanghai Jiao \\ Tong University School of Medicine (SJTU-SM), Shanghai 200025, China \\ Correspondence to: Ying Lu, email: stove@shsmu.edu.cn \\ Keywords: DNA damage; DNA damage response; pyruvate kinase; $\gamma$-H2AX; genomic instability \\ Received: April 27, $2017 \quad$ Accepted: October 28, $2017 \quad$ Published: November 17, 2017 \\ Copyright: Xia et al. This is an open-access article distributed under the terms of the Creative Commons Attribution License 3.0 (CC \\ BY 3.0), which permits unrestricted use, distribution, and reproduction in any medium, provided the original author and source are \\ credited.
}

\section{ABSTRACT}

Pyruvate kinase (PK) catalyzes the conversion of phosphoenolpyruvate and ADP to pyruvate and ATP, a rate-limiting reaction in glycolysis. M2 isoform of PK (PKM2) is the predominant form of PK expressed in tumors. In addition to its well established cytosolic functions as a glycolytic enzyme, PKM2 displays nuclear localization and important nonmetabolic functions in tumorigenesis. Herein, we report that nuclear PKM2 interacts with histone H2AX under DNA damage conditions. Depletion of PKM2 decreased the level of serine 139-phosphorylated H2AX $(\gamma-\mathrm{H} 2 \mathrm{AX})$ in response to DNA damage. The in vitro kinase assay reveals that PKM2 directly phosphorylates H2AX at serine 139, which is abolished by the deletion of FBP-binding pocket of PKM2 (PKM2Del $^{515-520}$ ). Replacement of wild type PKM2 with the kinase dead mutant PKM2-Del ${ }^{515-520}$ leads to decreased cell proliferation and chromosomal aberrations under DNA damage conditions. Together, we propose that PKM2 promotes genomic instability in tumor cells which involves direct phosphorylation of H2AX. These findings reveal PKM2 as a novel modulator for genomic instability in tumor cells.

\section{INTRODUCTION}

Cancer cells have increased glucose uptake and lactate production with concomitant decreased oxygen consumption, a phenomenon known as aerobic glycolysis or the Warburg effect. Previous works suggested that expression of pyruvate kinase M2 (PKM2) promotes aerobic glycolysis and plays a critical role in tumorigenesis [1-6]. Pyruvate kinase is the final and rate-limiting enzyme in glycolysis that catalyzes the conversion of phosphoenolpyruvate (PEP) and ADP to pyruvate and ATP. It has been known that PKM gene can express two isoforms by alternative RNA splicing, that is, pyruvate kinase M1 (PKM1) and PKM2 [7]. The highly active PKM1, which forms stable tetramers, is expressed in normal adult tissues such as the heart, brain and skeletal muscle. In contrast, PKM2 can be allosterically regulated by metabolic intermediates such as fructose-1, 6-bisphosphate
(FBP) and is convertible between a dimer with low pyruvate kinase activity and a FBP-bound tetramer with high pyruvate kinase activity [8-10]. PKM2 is expressed during embryogenesis and is the predominant form in tumors of different types [11-14]. A large body of evidence supports the notion that PKM2 expression correlates with tumorigenesis and poor prognosis for patients with many kinds of cancers, as reviewed [14]. Mechanistically, it was shown that tumor cells develop multiple post-translational strategies to decrease enzymatic activity of PKM2 including phosphotyrosine-binding, phosphorylation, acetylation and oxidation, leading to the accumulation of glycolytic intermediates for biosynthetic reactions to support proliferation [15-18]. These inhibitory effects on PKM2 activity occur in response to various stimuli that tumor cells may encounter during tumor initiation or maintenance, such as excessive growth factors, high glucose or high reactive oxygen species concentrations [15-18]. 
More recently, it was noted that PKM2 translocates to the nucleus under certain circumstances such as interleukin-3, epithelial growth factor (EGF), ultraviolet (UV) light and $\mathrm{H}_{2} \mathrm{O}_{2}$ treatment [19-22]. Nuclear PKM2 displays intriguing non-glycolytic functions including phosphorylating some nuclear proteins such as histone H3 [2, 23], signal transducer and activator of transcription 3 (stat3) [24], Bub3 [25], and myosin light chain 2 (MLC2) [26], for which PKM2 uses the high-energy phosphate from PEP but not ATP as a phosphate donor, proposing that PKM2 in cancer cells presents protein kinase activity. More recently, we also reported that the nuclear PKM2 interacts directly with P53 protein and inhibits P53-dependent transactivation of the P21 gene, leading to a nonstop $G_{1}$ phase in cancer cells exposed to DNA-damaging agent [27]. Thus nuclear PKM2 is linked to non-metabolic processes of cancer cells such as proliferation, cell cycle, apoptosis, epithelialmesenchymal transition and angiogenesis [19, 21, 24, 25, 28-34]. In this report, we show that DNA damage stimulus induces a direct interaction between PKM2 and H2AX. PKM2 phosphorylates $\mathrm{H} 2 \mathrm{AX}$ at serine 139, generating $\gamma-\mathrm{H} 2 \mathrm{AX}$ and promotes genomic instability following DNA damage.

\section{RESULTS}

\section{Nuclear PKM2 interacts with H2AX upon DNA damage}

To explore the potential functions of nuclear PKM2 during DNA damage response (DDR), we previously performed immunoprecipitation-coupled liquid chromatography-mass spectrometry/mass spectrometry (LC-MS/MS) using anti-PKM2 antibody in human breast cancer cell line MCF7 and identified a number of nuclear proteins in DNA damage signaling as PKM2 binding partners, among which histone $\mathrm{H} 2 \mathrm{AX}$ appeared (Figure 1A and 1B) [27]. Herein, we further confirmed the potential interaction of PKM2 with H2AX by coimmunoprecipitation (co-IP) based immunoblots. The results showed that anti-PKM2 antibody could pull down $\mathrm{H} 2 \mathrm{AX}$ in MCF7 cells treated with etoposide but not untreated MCF7 cells (Figure 1B and 1C). GST-pull down assay further demonstrated a direct binding of recombinant PKM2 with GST-H2AX (Figure 1D). In response to DNA damage, $\mathrm{H} 2 \mathrm{AX}$ is rapidly phosphorylated at serine (Ser) 139 to form $\gamma$-H2AX by phosphatidylinositol 3-kinaserelated kinases (PIKK)-family kinases, serving as an early and sensitive marker for DNA double strand breaks (DSB) [35-37]. We next investigated the association of PKM2 with $\gamma$-H2AX. As depicted in Figure 1C, anti-PKM2 antibody could pull down $\gamma$-H2AX in the etoposidetreated MCF7 cells, and anti- $\gamma-\mathrm{H} 2 \mathrm{AX}$ antibody also precipitated PKM2 under DNA damage conditions (Figure 1E). Moreover, immunoflurescent staining showed that nuclear PKM2 was co-localized with $\gamma$-H2AX-positive foci in MCF7 cells exposed to etoposide (Figure 1F). Collectively, these data demonstrated that PKM2 binds with $\mathrm{H} 2 \mathrm{AX}$ in response to DNA damage stimulus.

\section{PKM2 promotes H2AX phosphorylation during DDR}

We next asked whether PKM2 would affect H2AX phosphorylation due to their interaction during DDR. To this end, a pair of small hairpin RNAs (shRNAs) specifically against PKM2 (shPKM2\#1) was transfected into MCF7 (Figure 2A, Supplementary Figure 1A and 1B) and human lung cancer cell A549 (Supplementary Figure 1C), together with a non-specific shRNA as a negative control (NC). Immunoblots and immunofluorescent staining revealed that the shPKM2\#1 but not NC effectively silenced PKM2 (Figure 2A and Supplementary Figure 1A-1C). Of note, the specific shPKM2\#1 had no influence on PKM1 expression in MCF7 cells (Figure 2A). Then, these MCF7 cells were challenged with etoposide or irradiated by UV light. Etoposide treatment (Figure 2A and 2B) or UV irradiation (Figure $2 \mathrm{C}$ ) rapidly and significantly induced the formation of $\gamma-\mathrm{H} 2 \mathrm{AX}$, indicating occurrence of DNA damage. Of significance, the silence of PKM2 expression remarkably inhibited both etoposide and UV treatment-induced $\gamma-\mathrm{H} 2 \mathrm{AX}$ formation (Figure 2A-2C). Similar results could also be obtained in MCF7 cells transfected with another pair of shRNAs specifically against PKM2 (shPKM2\#2) (Supplementary Figure 1A) and other shPKM2\#1-transfected cancer cell lines such as A549 (Supplementary Figure 1C) and human leukemic NB4 cells (Supplementary Figure 1D). In line with these observations, foci of mediator of DNA damage checkpoint protein 1 (MDC1), a major adaptor for transducing DNA damage and repair signal following $\mathrm{H} 2 \mathrm{AX}$ phosphorylation $[38,39]$, was also diminished in response to etoposide in PKM2-depleted MCF7 cells (Supplementary Figure 1E). To confirm that the inhibitory DDR is specifically due to the silencing of PKM2, we re-introduced wild type PKM2 (PKM2-WT) into shPKM2\#1-transfected MCF7 and NB4 cells. The results demonstrated that re-expressions of PKM2 could rescue etoposide-induced $\gamma$-H2AX in shPKM2\#1-transfected MCF7 (Figure 2D) and NB4 cells (Supplementary Figure $1 \mathrm{~F}$ and $1 \mathrm{G})$. In addition, the rescuing effect was also conferred by PKM2-R399E mutant, a dimeric form of PKM2 (Figures 2D, Supplementary Figure $1 \mathrm{~F}$ and $1 \mathrm{G})[24,25]$. Furthermore, stimulating the nuclear accumulation of PKM2 by EGF treatment [2, 30] significantly enhanced etoposide-induced $\gamma-\mathrm{H} 2 \mathrm{AX}$ formation (Figure 2E and Supplementary Figure 2). Collectively, these results support that nuclear PKM2 promotes $\mathrm{H} 2 \mathrm{AX}$ phosphorylation and cellular response to DNA damage. 
A

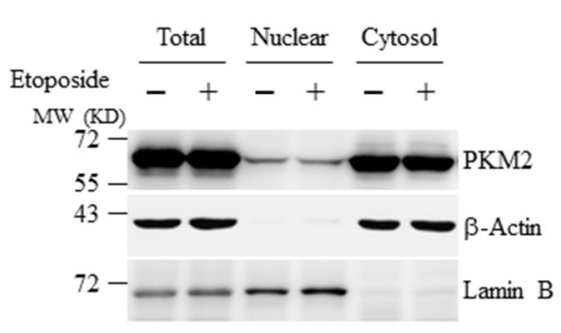

B

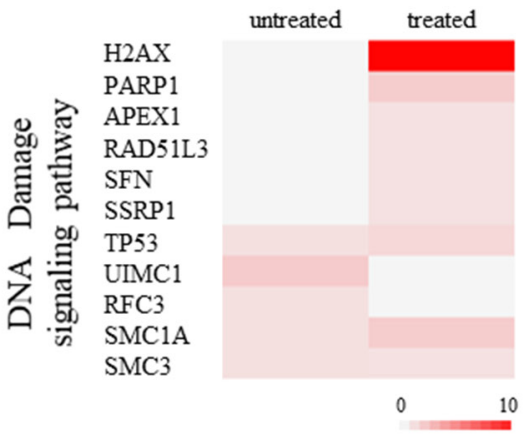

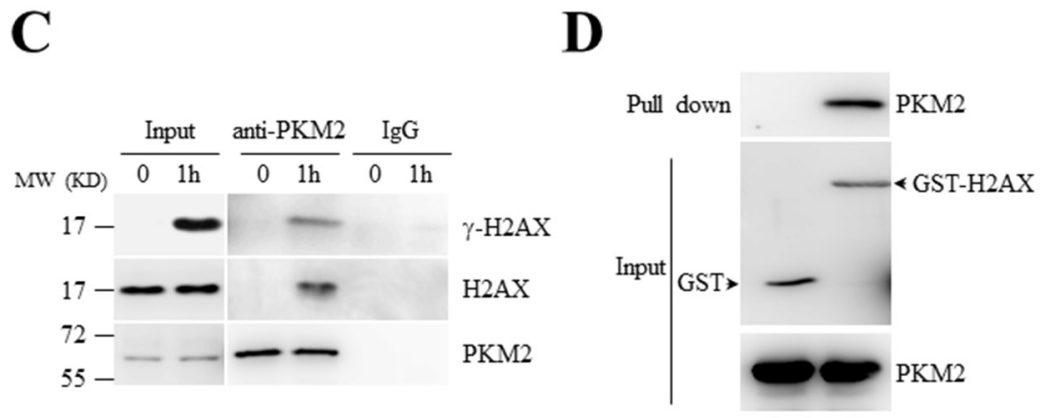

$\mathbf{E}$
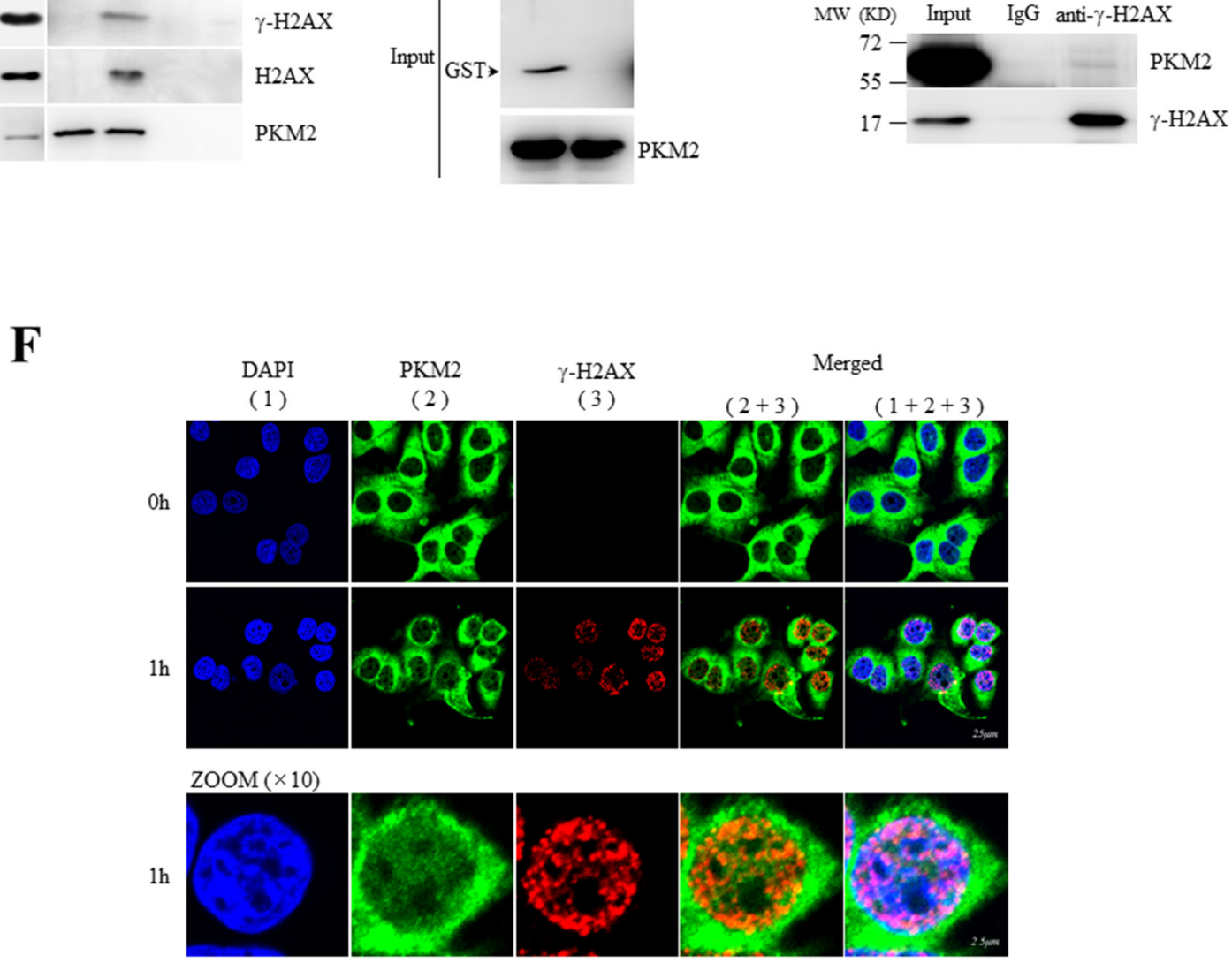

Figure 1: Nuclear PKM2 interacts with H2AX upon DNA damage. (A) Cytosolic and nuclear extracts were prepared from MCF7 cells treated with or without etoposide, followed by western blot analysis for the indicated proteins. LaminB was a nuclear marker, and $\beta$-actin acted as a cytosol marker. (B) Heat map of gene ontology (GO) for DNA damage signaling pathway based upon the identified PKM2-interacting proteins from LC-MS/MS. GO analysis (DAVID 6.7) was applied to the specific PKM2-associated complex under etoposide treatment and untreatment for molecular function and biological process enrichment [27]. The colors in the map represent the quantitative value (normalized total spectra) according to the Scaffold_4.3.3. Color code ranges from 0 to 10. (C) Co-IP analysis of the interaction between endogenous PKM2 and H2AX or $\gamma-\mathrm{H} 2 \mathrm{AX}$ using antibodies against PKM2 in MCF7 cells treated with or without etoposide for 1 hour. IP using rabbit IgG was a negative control. Input, 10\% whole cell lysate. (D) GST pull-down analysis of H2AX with PKM2 using purified PKM2 and GST-tagged H2AX fusion protein. (E) Co-IP analysis of the interaction between endogenous PKM2 and $\gamma-\mathrm{H} 2 \mathrm{AX}$ using antibodies against $\gamma$-H2AXin MCF7 cells treated with etoposide. (F) Immunofluorescent staining of endogenous PKM2 and $\gamma-\mathrm{H} 2 \mathrm{AX}$ in MCF7 cells treated with or without etoposide for 1 hour. The bottom panel showed the amplified images for cells lined with white line. All these experiments were repeated at least for three times with the same results. 
$\mathbf{A}$

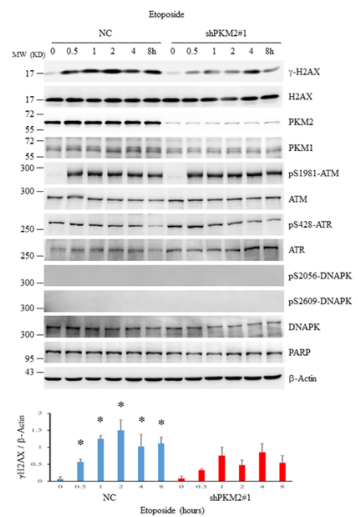

C

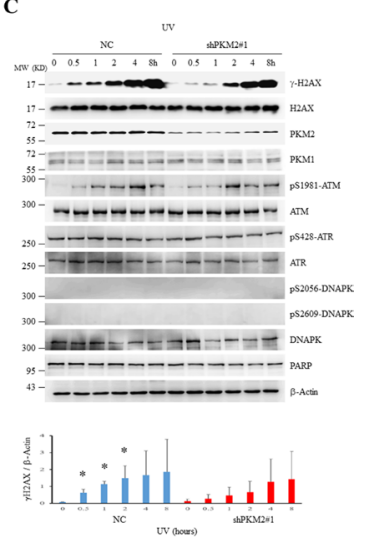

B

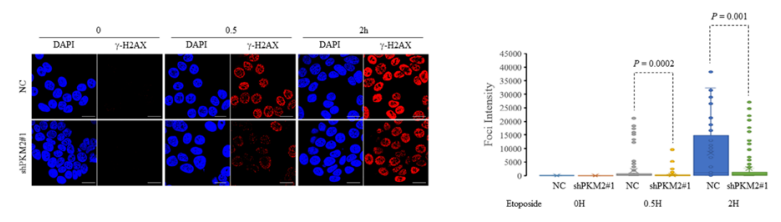

D

$\mathbf{E}$
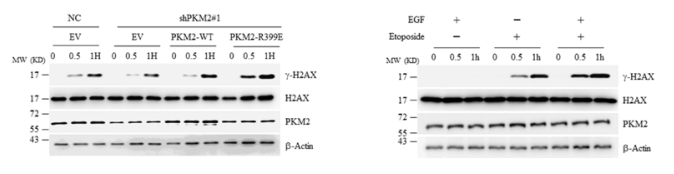

F

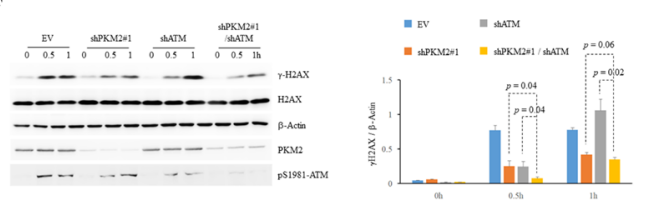

G
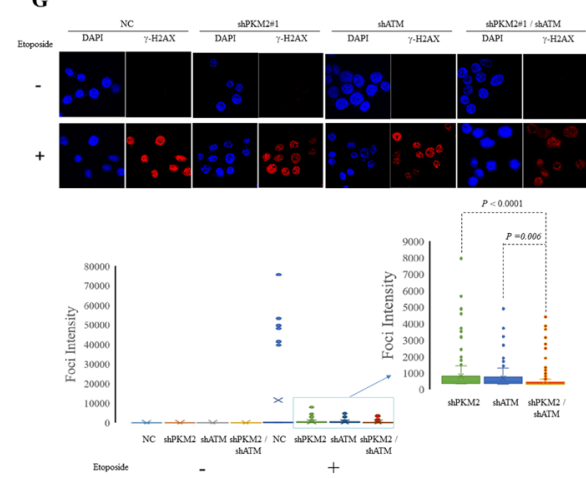

Figure 2: PKM2 promotes DDR. (A-C) MCF7 cells infected with shPKM2\#1 or NC were exposed to etoposide (A and B) or UV (C) for hours as indicated, followed by immunoblots for the indicated proteins (A and C) or immunofluorescent analyses (B) with DAPI co-staining. The protein bands on the gels were quantified by densitometry and shown on the bottom panels (A and C). ${ }^{*} p<0.05$ versus shPKM2. The intensity of H2AX foci was quantified by ImageJ Software and was shown on the right panel (B). (D) The shPKM2\#1 or NC-infected MCF7 cells were transfected with empty vector (EV), wild type (WT) or R399E mutant PKM2, and treated with etoposide for the indicated hours, followed by immunoblots for the indicated proteins. (E) MCF7 cells exposed to EGF $(100 \mathrm{ng} / \mathrm{ml})$ for 6 hours were treated with etoposide for the indicated hours, followed by immunoblots for the indicated proteins. (F) MCF7 cells infected with NC, shPKM2\#1 or/and shATM were exposed to etoposide for indicated hours, followed by immunoblots for the indicated proteins. The protein bands on the gels were quantified by densitometry and shown on the right panel. (G) Immunofluorescent staining of $\gamma$-H2AX in MCF7 cells infected with NC, shPKM2\#1 or/and shATM treated with or without etoposide for 0.5 hour. The intensity of H2AX foci was quantified by ImageJ Software and was shown on the bottom panel. All these experiments were repeated at least for three times with the same results. 
As mentioned above, phosphorylation of $\mathrm{H} 2 \mathrm{AX}$ at Ser 139 in response to DNA damage is conducted by PIKK-family kinases that include ATM (ataxia telangiectasia mutated), ATR (ATM and Rad3-related) and DNAPK (DNA-dependent protein kinase). In order to elucidate whether PKM2 promotes $\mathrm{H} 2 \mathrm{AX}$ phosphorylation through PIKK family member, we firstly detected the activation of the PIKK members using phosphorylation site-specific antibodies. As shown in Figure 2A and $2 \mathrm{C}$, treatment of MCF7 cells with etoposide or UV resulted in significant activation of ATM, as determined by immunoblots using antibody selective for Ser-1981 phosphorylated ATM. In contrast, phosphorylation of ATR or DNAPK, was not apparently induced upon the exposure of etoposide or UV, in agreement with ATM being the principal kinase for $\gamma$-H2AX formation
A

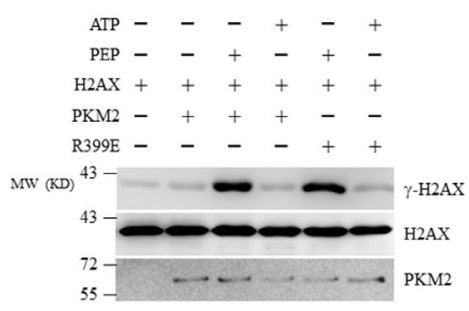

D

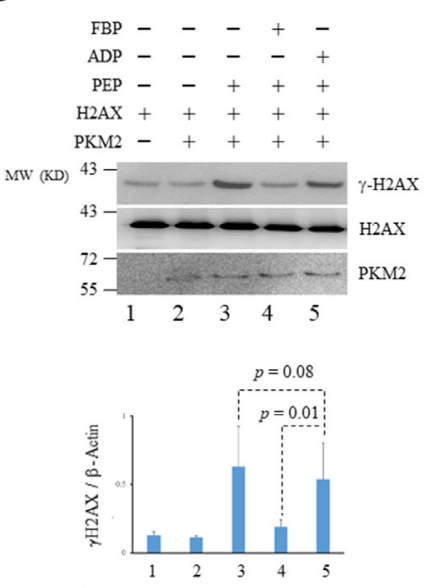

G

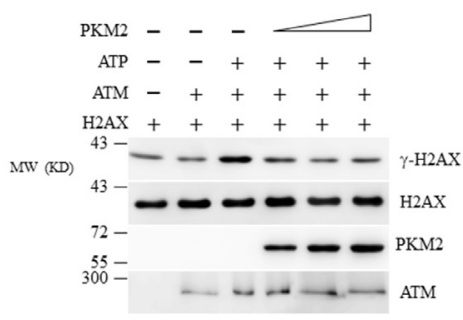

B

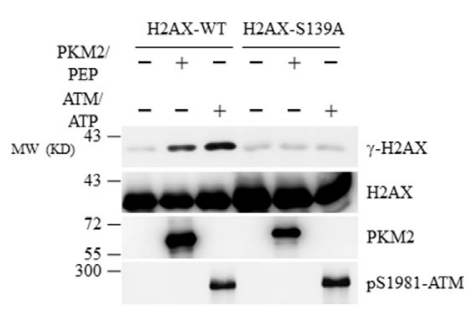

$\mathbf{E}$

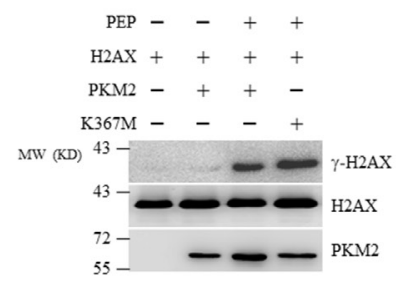

C

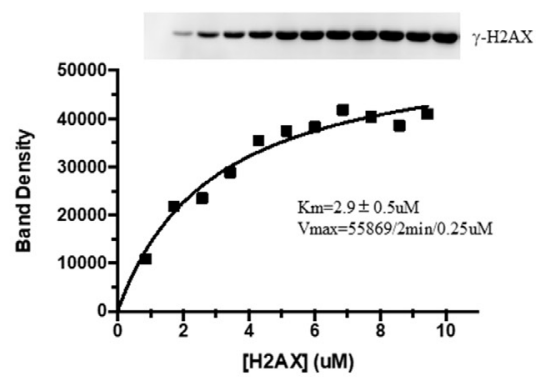

$\mathbf{F}$
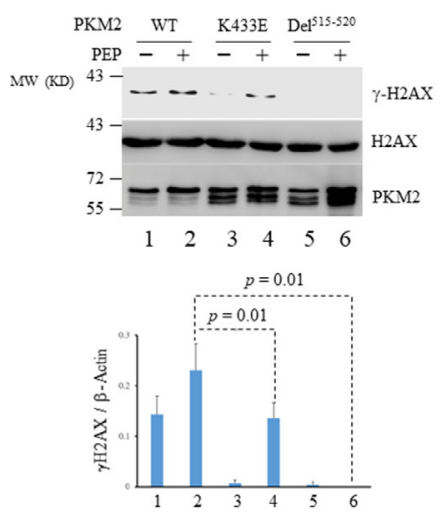

H

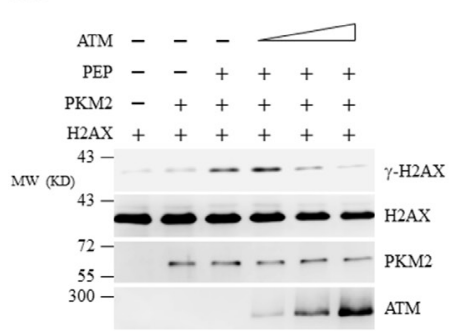

Figure 3: PKM2 phosphorylates H2AX at Ser139 in vitro. (A) Purified recombinant PKM2-WT or PKM2-R399E mutant was incubated with recombinant GST-H2AX in the presence of PEP or ATP. H2AX, $\gamma$-H2AX and PKM2 were detected by immunoblotting. (B) The in vitro kinase reactions were performed by incubating recombinant PKM2 or ATM with WT GST-H2AX or GST-H2AX-S139A mutant in the presence of PEP (for PKM2) or ATP (for ATM). (C) PKM2 $(0.25 \mu \mathrm{M}$ ) was incubated with varied purified H2AX in the presence of excess PEP at room temperature for $2 \mathrm{~min}$. The reaction mixtures were then analyzed by Western blot using indicated antibodies (upper panel). The phosphorylated H2AX protein bands were quantified by densitometry and the kinetic constants were determined by fitting the data with Michaelis-Menten equation using GraphPad Prism. (D) Phosphorylation of GST-H2AX by recombinant PKM2 in the presence of FBP, ADP or PEP was detected by immunoblotting. (E, F) The in vitro kinase assay was carried out by mixing WT PKM2 or its mutants as indicated with GST-H2AX. The protein bands on the gels were quantified by densitometry and shown on the bottom panel $(\mathrm{D}, \mathrm{F}) .(\mathbf{G}, \mathbf{H})$ Phosphorylation of recombinant H2AX by ATM or PKM2 in the presence of escalating concentration of PKM2 (G) or ATM $(\mathrm{H})$ was analyzed by in vitro kinase assay. Immunoblots were performed for indicated proteins. All these experiments were repeated at least for three times with the same results. 
following DNA damage induced by agents that cause genotoxic stress [40]. Notably, consistent with previous reports showing that UV is different from etoposide (DNA topoisomerase II inhibitor) in triggering PIKK signals $[41,42]$, distinct pattern of ATM activation and $\gamma-\mathrm{H} 2 \mathrm{AX}$ formation in response to etoposide and UV in MCF7 cells was observed. High level of phosphorylated ATM and $\mathrm{H} 2 \mathrm{AX}$ was rapidly induced and maintained from 0.5 hour upon etoposide treatment in contrast to a gradually induced activation in response to UV (Figure 2A and 2C). Importantly, although depletion of PKM2 attenuated the $\gamma$-H2AX formation, it did not affect the level of Ser-1981 phosphorylated ATM (Figure 2A and 2C). Moreover, knockdown PKM2 in ATM-depleted MCF7 cells further reduced the level of $\gamma-\mathrm{H} 2 \mathrm{AX}$ at 0.5 hour after etoposide treatment (Figure $2 \mathrm{~F}$ and $2 \mathrm{G}$ ), suggesting that PKM2 could contribute to the phosphorylation of H2AX during DDR through mechanisms other than activating ATM signals.

\section{PKM2 directly phosphorylates H2AX at Ser139}

Nuclear PKM2 has been reported to display protein kinase activity towards a number of substrates for which PKM2 uses PEP but not ATP as a phosphate donor [2, 23, $24,30]$. Considering that the activity of kinases known to be responsible for generation of $\gamma-\mathrm{H} 2 \mathrm{AX}$ was not changed upon PKM2 depletion, we postulated that H2AX might be directly phosphorylated by PKM2. We set up in vitro kinase reaction and observed that recombinant PKM2 could phosphorylate $\mathrm{H} 2 \mathrm{AX}$ in the presence of PEP [12, 24], but not ATP (Figure 3A), indicating that PKM2 presents kinase activity on H2AX with the PEP as phosphate donor. Consistent with the previous reports [43-45], recombinant ATM phosphorylated H2AX but not H2AX-S139A mutant in the presence of ATP (Figure 3B). Likewise, PKM2 failed to phosphorylate H2AXS139A in the presence of PEP (Figure 3B), suggesting that the PKM2 and ATM phosphorylate the same serine of H2AX. Furthermore, the dimeric PKM2-R399E mutant, which was reported to still present protein kinase activity as dimers [24], also phosphorylated H2AX to a similar degree to PKM2-WT in the presence of PEP (Figure 3A).

Next, we assessed the kinetic parameters for the reaction between PKM2 and $\mathrm{H} 2 \mathrm{AX}$ by densitometry. We used an optimized reaction condition where $0.25 \mathrm{uM}$ PKM2 was incubated with various concentrations of $\mathrm{H} 2 \mathrm{AX}$ in the presence of excess PEP at room temperature. The reaction mixtures were then analyzed by Western blot. The phosphorylated $\mathrm{H} 2 \mathrm{AX}$ protein bands were quantified by densitometry and the kinetic constants were determined by fitting the data with Michaelis-Menten equation using Graph Pad Prism. As depicted in Figure 3C, H2AX, as a substrate, could be phosphorylated by PKM2 with a Km of $2.9 \pm 0.5 \mathrm{uM}$.

PKM2 is a tightly regulated enzyme which responds not only to the availability of PEP and ADP substrates, but also to FBP, a glycolysis intermediate acting as an allosteric activator of PKM2 [9, 46]. To address whether ADP or/and FBP-binding site is involved in protein kinase activity of PKM2 towards $\mathrm{H} 2 \mathrm{AX}$, we carried out competition kinase analysis in the presence of ADP or FBP. The results demonstrated that FBP markedly reduced PKM2-induced $\gamma-\mathrm{H} 2 \mathrm{AX}$ formation (Figure 3D). In contrast, the addition of ADP did not significantly affect the phosphorylation of $\mathrm{H} 2 \mathrm{AX}$ by PKM2, suggesting that the protein kinase active site might be distinct from the pyruvate kinase active site [47]. In line with this finding, PKM2 K367M mutant, which lost the ADP-binding ability [2], still exhibited similar protein kinase activity with PKM2-WT (Figure 3E). However, deletion of the FBPbinding pocket of PKM2 (Del ${ }^{515-520}$ ) abolished its kinase activity on H2AX (Figure 3F). Mutation of lysine 433 $(\mathrm{K} 433 \mathrm{E})$, which is located at the lip of the pocket $[15,48]$, also showed a slightly decreased kinase activity compared with its WT counterpart (Figure 3F). Because both Del ${ }^{515-}$ ${ }^{520}$ and K433E could bind with $\mathrm{H} 2 \mathrm{AX}$ as evaluated by GST-pull down assays (Supplementary Figure 3), we postulated that the decreased kinase activity may be due to lower kinectics of the PKM2 mutants for this reaction which required further investigation. Taken together, these results indicate that FBP-binding sites of PKM2 is critical for the protein kinase activity of PKM2.

We next detected the potential association of PKM2 with ATM on H2AX phosphorylation using in vitro kinase assay. As shown in Figure $3 \mathrm{G}$ and $3 \mathrm{H}$, recombinant PKM2 and ATM interfered with the other's kinase activity in a dose dependent manner in vitro. These results demonstrated that ATM and PKM2 work competitively in phosphorylating $\mathrm{H} 2 \mathrm{AX}$ in vitro.

\section{PKM2 phosphorylates H2AX under DNA damage stimuli in vivo}

To test whether PKM2 is a potent H2AX kinase in vivo, xenograft experiments followed by immunoblots analysis of $\gamma-\mathrm{H} 2 \mathrm{AX}$ in the tumors were performed. MCF7 cells infected with $\mathrm{NC}$ or shPKM2\#1 were injected subcutaneously into the mammary fat pad of the nude mice followed by etoposide treatment for 7 days. The tumors were collected two weeks afterwards and subjected to western blots. As shown in Figure 4, etoposide treatment induced significant $\gamma-\mathrm{H} 2 \mathrm{AX}$ formation in contrast to etoposide-untreated group. Compare to $\mathrm{NC}$ tumors, administration of etoposide led to decreased $\gamma-\mathrm{H} 2 \mathrm{AX}$ in shPKM2 tumors (Figure 4), demonstrating that PKM2 phosphorylates $\mathrm{H} 2 \mathrm{AX}$ in vivo.

\section{PKM2 promotes cell growth with increased DNA damage and chromosomal aberrations following DDR}

We previously showed that PKM2 promotes tumor growth under DNA damage [27]. To further clarify the 
role of PKM2 protein kinase activity towards $\mathrm{H} 2 \mathrm{AX}$ in promoting cell proliferation, we created a cell line by stable expression of Del ${ }^{515-520}$ in PKM2-depleted MCF7 cells. Cell counting kit-8 (CCK-8) assay showed that the PKM2 expression, whether wild type or Del ${ }^{515-520}$ did not cause apparent change in cell proliferation without etoposide administration (Figure 5A). However, consistent with our previous report [27], treatment of etoposide induced a decreased proliferation of PKM2-depleted MCF7, which could be rescued by expression of WT PKM2 (Figure 5B). In contrast, expression of Del ${ }^{515-520} \mathrm{did}$ not fully restore the proliferation rate as WT PKM2 did (Figure 5B), suggesting that the protein kinase activity, at least partially, mediated the effects of PKM2 in promoting cell proliferation following DDR.

To address whether PKM2 induces higher level of damage to DNA in response to genotoxic stress, we evaluated DNA strand breaks using the comet assay, which can effectively detect single and double strand breaks in DNA under alkaline conditions [49, 50]. The results showed that etoposide and UV induced significant DNA strand breaks in a time dependent manner (Figure 6). Compared to NC cells, etoposide and UV induced decreased level of DNA strand breaks in PKM2-depleted MCF7 cells (Figure 6), indicating that PKM2 increased the damage to DNA.

Because increased rates of DNA damage if overwhelming the ability of cellular repair systems may cause genomic instability [51-53], which is a hallmark of cancer cells, we further looked into the genomic integrity in the presence or absence of PKM2 by staining chromosomes 2, 3 and 5. Our results demonstrated that knockdown of PKM2 alone did not yield significant difference in chromosomal aberrations (Figure 7). However, etoposide-treated PKM2-depleted MCF7 cells displayed a decrease in chromosomal aberrations in these three chromosomes (Figure 7) compared with NC cells, while re-expression of PKM2-WT in MCF7 cells
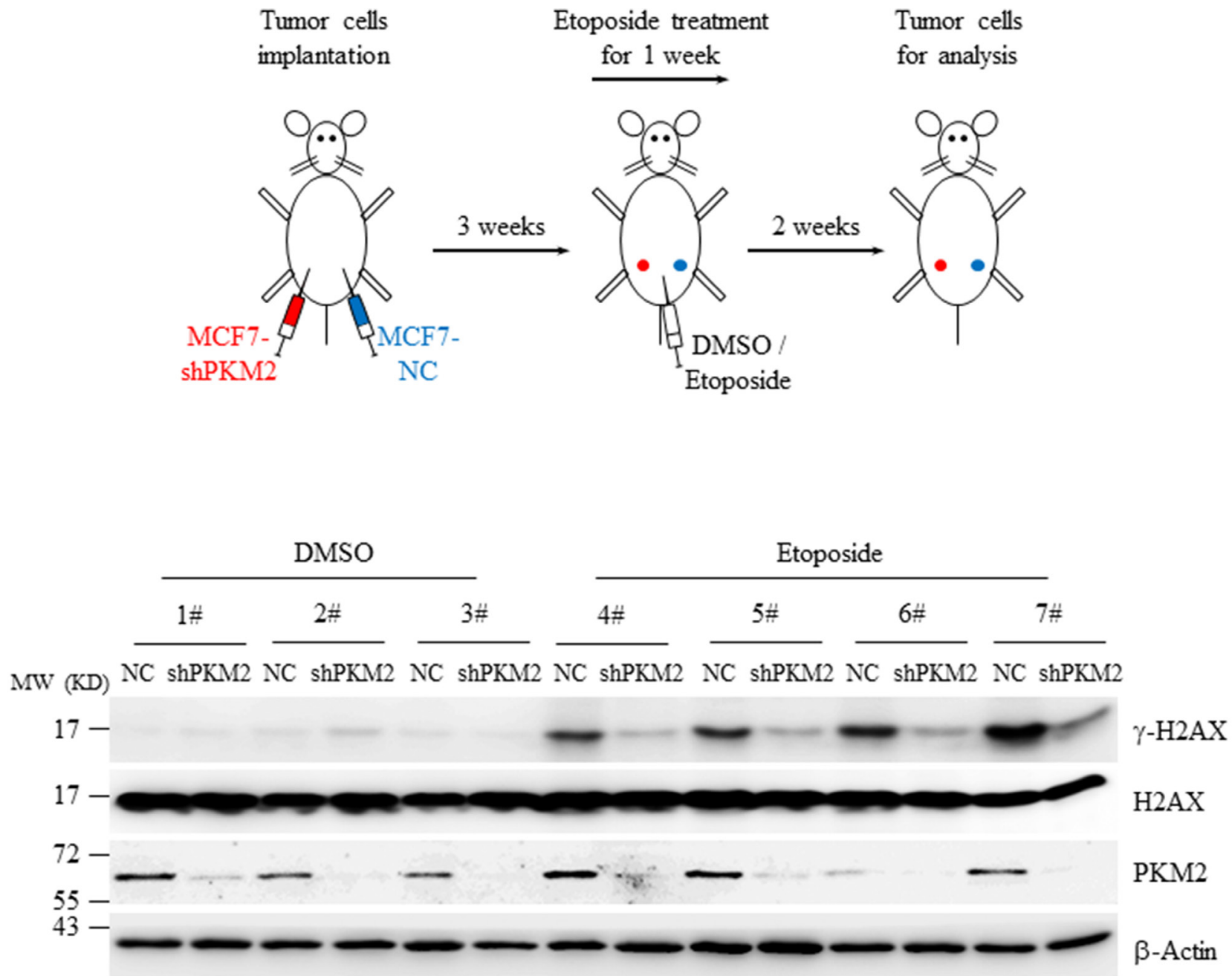

Figure 4: Knockdown of PKM2 decreased $\boldsymbol{\gamma}$-H2AX level in xenografts. MCF7 cells infected with NC or shPKM2\#1 were injected into the left or right side of the mammary fat pad of nude mice and grown for three weeks. Afterwards, a dose of $0.1 \mathrm{mg} / \mathrm{kg}$ of etoposide was administrated intraperitoneally for 7 consecutive days. Two weeks later, the fresh tumors from the mice were collected, homogenated and subjected to western blot analysis with the indicated antibodies. 
could effectively restore etoposide-induced significant aberrations in the chromosome 5 detected (Figure 8). In contrast, PKM2-Del ${ }^{515-520}$ mutant which lost the ability to phosphorylate $\mathrm{H} 2 \mathrm{AX}$ (Figure $3 \mathrm{~F}$ ) failed to restore etoposide-induced chromosomal aberrations (Figure 8), indicating that the phosphorylation of $\mathrm{H} 2 \mathrm{AX}$ by PKM2 contributes to increased genomic instability following DNA damage. Collectively, our data suggested that PKM2 promoted tumor growth with increased DNA damage which may leads to high risk of genomic instability in response to DNA-damaging agents.

\section{DISCUSSION}

Phosphorylation of $\mathrm{H} 2 \mathrm{AX}$ at Ser 139, generating $\gamma-\mathrm{H} 2 \mathrm{AX}$, is an early and sensitive marker of DNA DSB. It is a key step in DDR that initiates the recruitment of downstream signaling and repair proteins such as MDC1 at the break sites, where $\gamma-\mathrm{H} 2 \mathrm{AX}$ foci is formed. H2AX can be phosphorylated by PIKK family proteins that include ATM, ATR and DNAPK. These three kinases distinguish in the kinetics of activation and the types of stimuli to which they respond best but function redundantly under
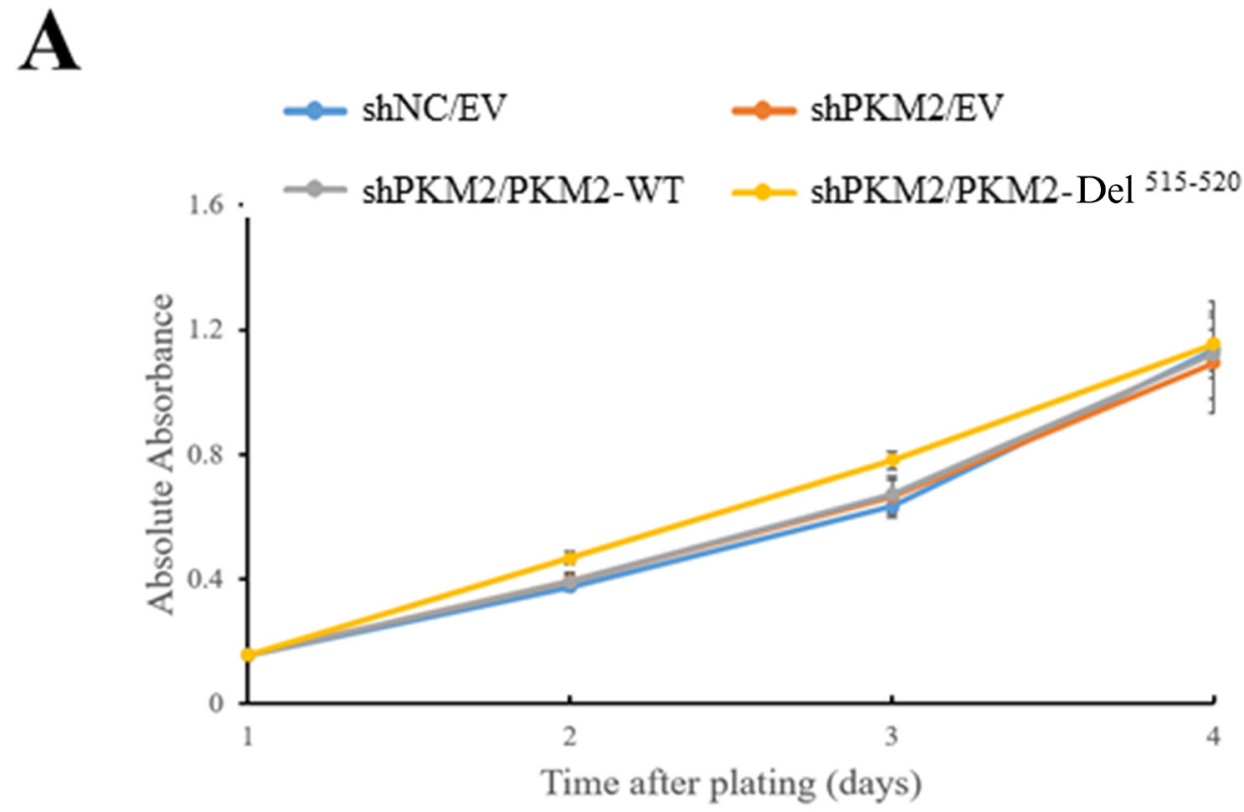

B

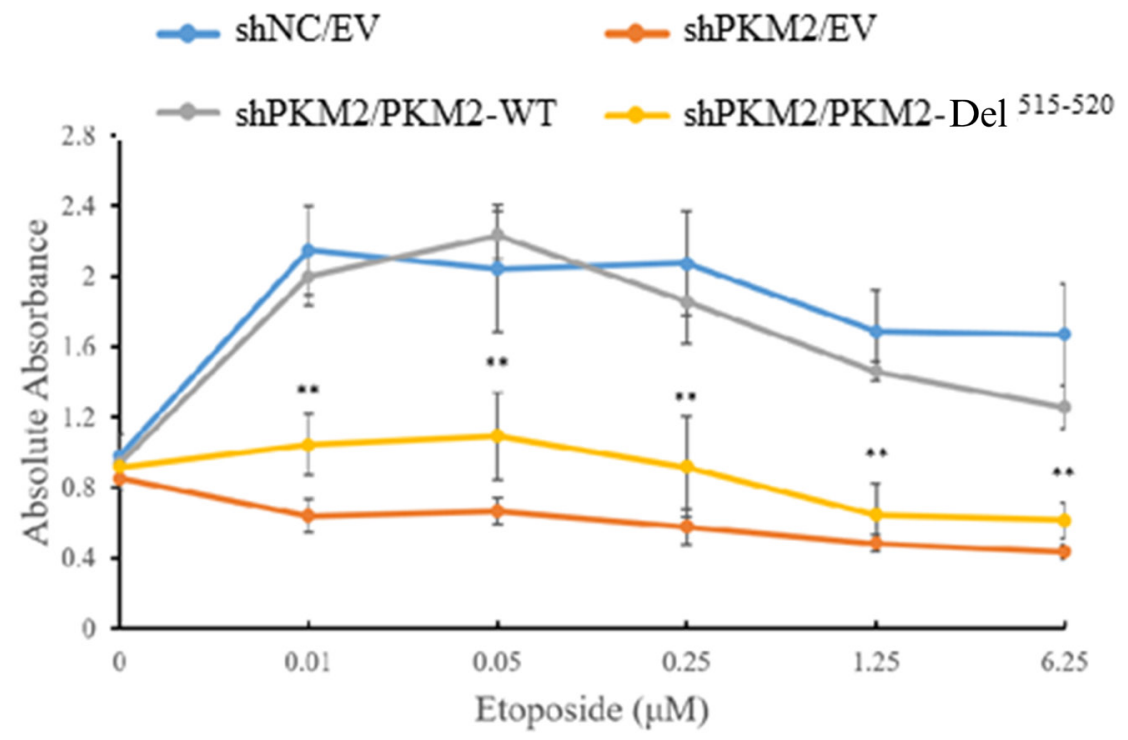

Figure 5: PKM2 promotes cell growth under DNA damage condition. Expression of empty vector (EV), wild type (WT) PKM2 or PKM2-Del ${ }^{515-520}$ mutant in PKM2-depleted MCF7 cells followed by treatment with (B) or without (A) etoposide. Then the cell proliferations were measured by CCK-8 assay. ${ }^{* *} p<0.01$ versus PKM2-WT. 

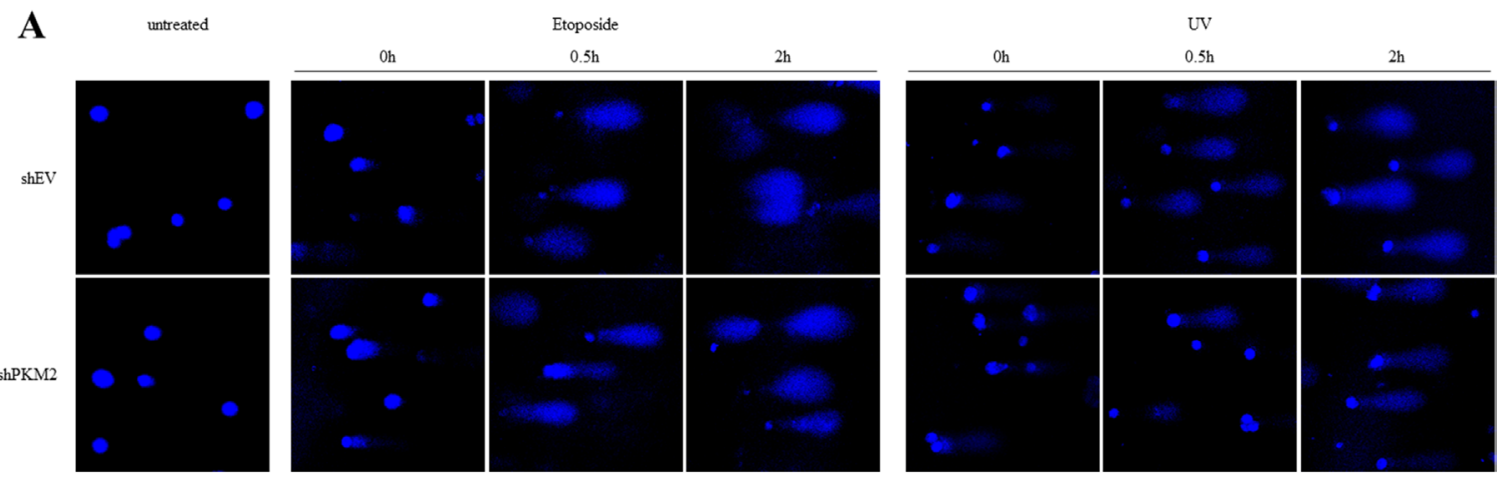

B
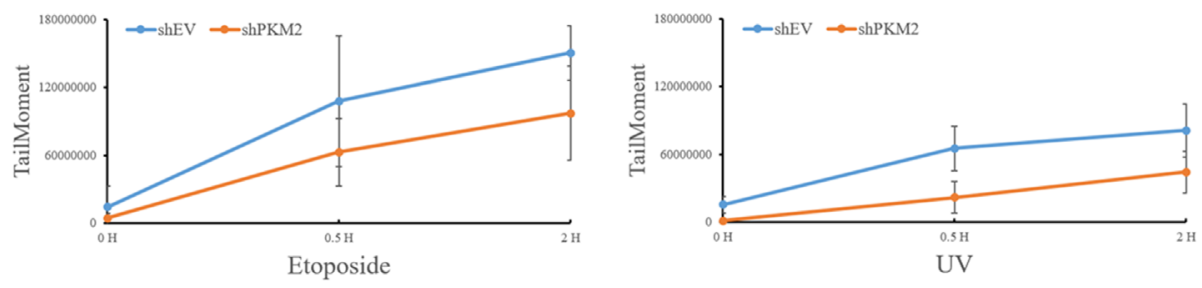

Figure 6: PKM2 increased chemical- and UV-damaged DNA. (A) MCF7 cells infected with shPKM2\#1 or NC were exposed to etoposide or UV for indicated hours, followed by detection of DNA damage through alkaline comet assay. (B) Images were analysed with an ImageJ software plugin Comet Assay from Microscopy Services Laboratory (https://www.med.unc.edu/microscopy) and levels of DNA damage were shown.

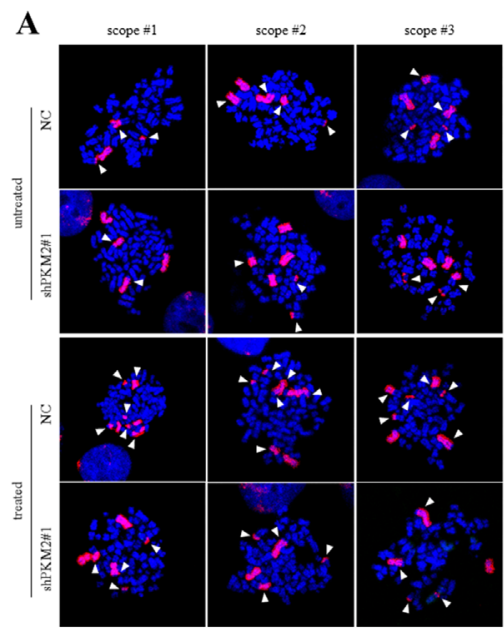

Chromosome 2

B

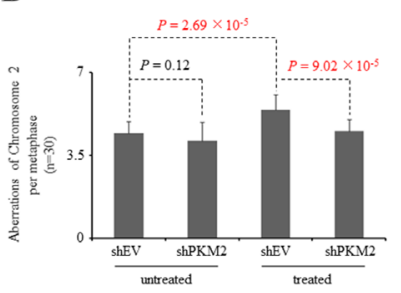

C

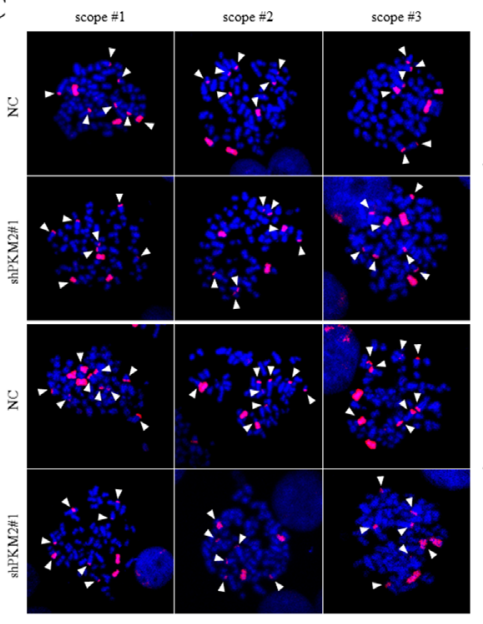

Chromosome 3

D

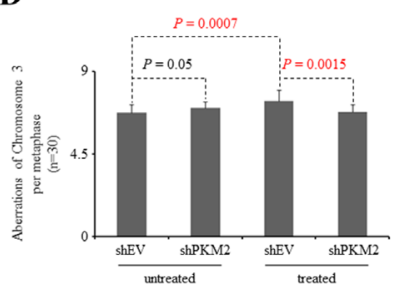

$\mathbf{E}$

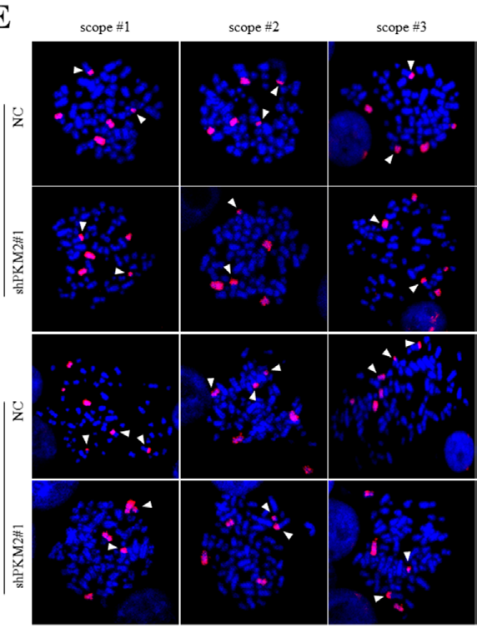

Chromosome 5

F

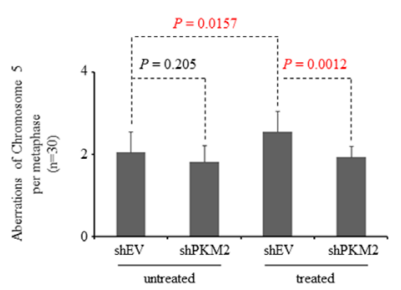

Figure 7: Knockdown of PKM2 reduces chromosomal aberrations following DDR. (A, C, E) Three representative metaphase spreads of MCF7 cells infected with NC or shPKM2\#1 either untreated or 24hr following etoposide treatment. Fluorescence in situ hybridization (FISH)-mediated whole chromosomal staining was used to identify aberrations of chromosome 2 (A), 3 (C) and 5 (E). (B, D, F) Quantification of total chromosome aberrations/metaphase (30 metaphases scored/group). Data are mean $\pm \mathrm{SD}$ of triplicates in an independent experiment, which were repeated at least for three times with the same results. 
most conditions [54]. Herein, we identified that PKM2 as a novel protein kinase targeting $\mathrm{H} 2 \mathrm{AX}$ when cells are challenged with DNA-damaging agents. Instead of using ATP as phosphate donor like ATM, PKM2 utilizes PEP when phosphorylating $\mathrm{H} 2 \mathrm{AX}$. This might be of particular importance for rapid-growing tumor cells because of the inadequate blood and oxygen supply which limits the production of ATP. Furthermore, our results showed that PKM2 inhibits the kinase activity of ATM towards H2AX in vitro. Therefore, we propose that phosphorylation of $\mathrm{H} 2 \mathrm{AX}$ by PKM2 to initiate DDR may act as an adaptive response in tumor cells exposed to genotoxic stress.

How the protein kinase activity of PKM2 is triggered upon DNA damage is of great interests.
The functions of PKM2, whether enzymatic activity or non-metabolic role identified heretofore, is largely associated with its conformation state. Unlike PKM1 which constitutively exists as a stable tetramer, PKM2 is convertible between enzyme-active tetramer and inactive dimer. As a protein kinase, it is active in the form of dimer when phosphorylating stat3 at tyrosine 705 [24], while both dimers and tetramers can phosphorylate Bub3 at tyrosine 207 [25]. The predominant form of nuclear PKM2 is dimer rather than tetramer in MCF7 cells [27], suggesting that the dimeric PKM2 contributes to the phosphorylation of $\mathrm{H} 2 \mathrm{AX}$ in cells. On the other hand, since the protein level of nuclear PKM2 was not changed upon DNA damage, a plausible mechanism
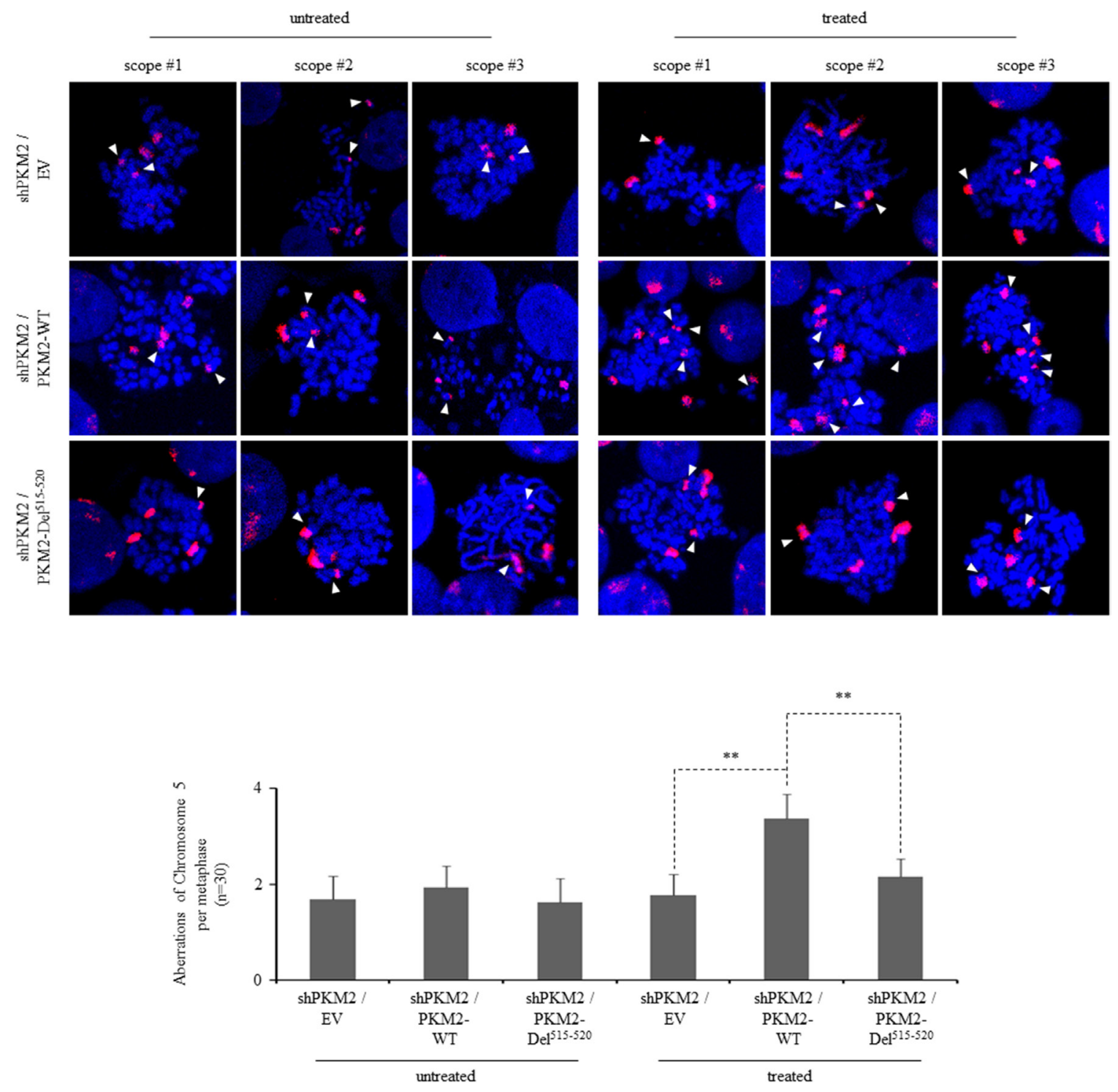

Figure 8: PKM2 expression increases chromosomal aberrations following DDR. Three representative metaphase spreads of MCF7 cells reconstitutively expressing empty vector (EV), PKM2-WT or PKM2-Del ${ }^{515-520}$ mutant either untreated or 24hr following etoposide treatment. FISH-mediated whole chromosomal staining was used to identify aberrations of chromosome 5 . Bottom panel shows the quantification of total chromosome aberrations/metaphase (30 metaphases scored/group). Data are mean \pm SD of triplicates in an independent experiment, which were repeated at least for three times with the same results. ${ }^{* *} p<0.01$ versus PKM2-WT. 
responsible for the activation of protein kinase activity would be post-translational modifications. A number of post-translational modifications including S37phosphorylation, Y105-phosphorylation and K433acetylation that may modulate nuclear PKM2 function $[20,28,55]$ were detected using site-specific antibodies. Neither the level of phosphorylation of PKM2 at S37, Y105 nor the acetylation at K433 was apparently changed upon etoposide treatment. However, immunofluorescent assay did show a colocalization of S37 phosphorylated PKM2 with $\gamma$-H2AX, indicating that S37 phosphorylation may participate in stimulating the protein kinase activity of PKM2 (data not shown). Further investigations should follow to identify the potential mechanism of the activation of protein kinase activity.

Genomic instability is an important hallmark of cancer which may result from increased frequency of genetic damages or interrupted DNA repair $[50,56]$. We observed that expression of PKM2 endows the tumor cells with increased amount of DNA damage and chromosomal aberrations after the cells were challenged with etoposide. More importantly, replacement of PKM2 with the kinase dead mutant diminished etoposide-induced chromosomal aberrations, suggesting a role of PKM2 in modulating genomic integrity through phosphorylating $\mathrm{H} 2 \mathrm{AX}$. Currently there is a lack of understanding as to exactly how PKM2 controls DNA damage and genomic instability. Meanwhile, the other DDR-related PKM2interacting proteins identified by LC-MS/MS such as APEX1 (apurinic/apyrimidinic endodeoxy ribonuclease 1) and RAD51L3 (DNA repair protein RAD51 homolog 4) may potentially provide plausible explanation and deserved to be further investigated.

Taken together, our data demonstrated that PKM2 phosphorylates $\mathrm{H} 2 \mathrm{AX}$ in response to DNA damage. We also showed that PKM2 modulate DNA damage and genomic instability following DDR. These observations reveal a novel role of PKM2 in tumorigenesis and establish a link between glycolytic enzyme and genomic instability.

\section{MATERIALS AND METHODS}

\section{Materials}

Etoposide (VP16) was purchased from Calbiochem. Fructose 1, 6-bisphosphate (FBP), phosphoenolpyruvic acid (PEP), adenosine diphosphate (ADP), adenosine triphosphate (ATP), hygromycin B were purchased from Sigma. Rabbit polyclonal antibodies against PKM2, H2AX, $\gamma$-H2AX, ATM, Phospho-ATM (Ser1981), ATR, Phospho-ATR (Ser428), DNAPK and phospho-DNAPK (Ser 2056), and $\beta$-actin were obtained from Cell Signaling Technology. Phospho-DNAPK (Ser 2609) antibody was purchased from Signal way Antibody (College Park). Goat antibody against LaminB was obtained from Santa Cruz
Biotechnology (Santa Cruz). Mouse antibody for $\gamma-\mathrm{H} 2 \mathrm{AX}$ were from Abcam. Monoclonal antibodies for His or GST were from Sigma.

\section{Cell culture}

Human MCF7 and A549 cells were maintained in Dulbecco's Modified Eagle's Medium (DMEM) supplemented with 10\% fetal bovine serum (FBS). MCF7 cells were cultured with $0.01 \mathrm{mg} / \mathrm{ml}$ human recombinant insulin (Sigma). NB4 cells were cultured in RPMI-1640 medium (Sigma) supplemented with $10 \%$ or $20 \%$ FBS. For triggering DDR, MCF7 cells were treated with $100 \mu \mathrm{M}$ etoposide or exposed to $40 \mathrm{~J} / \mathrm{m}^{2} \mathrm{UV}$. A549 or NB4 cells were exposed to $100 \mu \mathrm{M}$ or $1 \mu \mathrm{M}$ etoposide respectively.

\section{Vector construction}

Human PKM2 cDNA was amplified from MCF7 cells by RT-PCR and then cloned into psumo3 vector provided by Dr Aiwu Zhou to construct His-tagged PKM2 protein-expressing plasmid or into pBabe vector (Clontech) to generate psumo3-PKM2 and pBabe-PKM2. All point mutants of PKM2 (R399E, K367M, K433E, $\mathrm{De}^{515-520}$ ) were created utilizing QuickChange SiteDirected Mutagenesis Kit (Stratagene). The psumo3$\mathrm{H} 2 \mathrm{AX}$ were subcloned from $\mathrm{pGEX}-\mathrm{H} 2 \mathrm{AX}$ vector provided by Dr Huang Lei using the following primer pairs: 5'-TA TGGATCCTCGGGCCGCGGCAAGAC-3' (forward) and 5'-GTAGTCGACTTA GTACTCCTGGGAGGCC3'(reverse). pSIREN PKM2 shRNA was generated using CATCTACCACTTGCAATTA oligonucleotide targeting transcript of exon 10 of the PKM [2]. The pSIREN of ATM shRNA target sequence was AACATACTACTCAAAGACATT (PMID: 22123827). Non-sense mutations of C1170T, C1173T, T1174C and G1176T of PKM2 [2] were cloned into the rescuing plasmids pQCXIN Retrovial (Clontech). The sequences of all cDNA inserts of plasmids were confirmed by sequencing.

\section{Subcellular fractionation}

Cells were suspended in hypotonic buffer $(10 \mathrm{mM}$ Tris- $\mathrm{HCl}$, pH 7.9, 1.5mM MgCl $2,10 \mathrm{mM} \mathrm{KCl,} \mathrm{1mM} \mathrm{DTT,}$ 1 tablet/10ml EDTA-free complete protease inhibitor cocktail (Roche) and 1 tablet/10ml phosphatase inhibitor cocktail (Roche)) by a Dounce homogenizer (40 strokes). Nuclear pellets were separated from cytoplasm by centrifugation for 10 minutes at $1000 \mathrm{~g}$. The supernatants (cytoplasmic extract) were removed and transferred into new tubes. Nuclear pellets were washed with hypotonic buffer twice, and resuspended in the nuclear extraction buffer $\left(50 \mathrm{mM}\right.$ Tris- $\mathrm{HCl}$, pH 7.9, $1 \mathrm{mM} \mathrm{MgCl}_{2}, 1 \mathrm{mM}$ DTT, 0.1\% NP40, 250units/ml Benzonase (Sigma), 1 tablet/10ml EDTA-free complete protease inhibitor cocktail and 1 tablet/10ml phosphatase inhibitor cocktail) 
by sonication. The supernatants (nuclear extracts) were centrifuged for 10 minutes at $12,000 \mathrm{~g}$.

\section{Immunoprecipitation analysis}

Whole-cell extracts were prepared in $300 \mu$ l of lysis buffer (50mM HEPES, $50 \mathrm{mM} \mathrm{NaCl}, 0.1 \%$ Tween 20 , $10 \%$ glycerol, $20 \mathrm{mM}$ sodium pyrophosphate, $1 \mathrm{mM}$ dithiothreitol, plus protease inhibitors) and incubated overnight with indicated antibodies (including $\gamma$-H2AX and anti-PKM2) and protein A/G plus-agarose (Santa Cruz Biotechnology) at $4^{\circ} \mathrm{C}$. After IP, the beads were intensively washed with washing buffer $(50 \mathrm{mM}$ Tris- $\mathrm{HCl}$, pH 7.6; $300 \mathrm{mM} \mathrm{NaCl} ; 1 \mathrm{mM}$ EDTA; $0.5 \% \mathrm{NP}-40 ; 10 \%$ glycerol). Then the precipitates were analyzed by Western blot.

\section{Western blots}

Protein extracts were equally loaded on $10-12 \%$ SDS-polyacrylamide gel, and transferred to nitrocellulose membrane (Amersham Bioscience). The blots were stained with $0.2 \%$ Ponceau $S$ red to ensure equal protein loading. After blocking with 5\% nonfat milk in PBS, the membrane was incubated with indicated antibodies, followed by horseradish perioxidase (HRP)-linked secondary antibodies (Cell Signaling Technology). Detection was performed by chemiluminescence phototope-HRP kit (Cell Signaling Technology). The protein bands on the gels were quantified by densitometry. Scanning was performed at optimal exposure time where band intensity was proportional to the concentration of protein present. Gel photographic images were stored as GRAYSCALE pictures in the TIF format and were processed using ImageJ Software.

\section{Confocal microscopy}

Cells were treated as described in the text, harvested on slides and fixed. After permeabilization with $0.1 \%(\mathrm{v} / \mathrm{v})$ Triton X-100 in PBS and blocking with 2\% (w/v) BSA in PBS, cells were incubated overnight with the indicated antibodies followed by secondary antibodies conjugated either with Alexa Fluor 555 dye (Invitrogen) or Alexa Fluor 488 dye for $1 \mathrm{~h}$. Cellular DNA was counterstained with 4, 6-diamidino-2-phenylindole (DAPI; Molecular Probes). Fluorescence signals were detected on a Nikon A1R confocal laser microscope.

\section{Purification of recombinant proteins}

His-tagged WT and mutant PKM2 as well as GST-tagged $\mathrm{H} 2 \mathrm{AX}$ protein were expressed in bacteria BL21 (DE3) by induction with $0.5 \mathrm{mM}$ isopropylthiogalactopyranoside (IPTG) at $30^{\circ} \mathrm{C}$ and purified from the cytosol of the expressed cells by affinity chromatography on Ni-NTA-agarose (Qiagen).

\section{Size-exclusion chromatography}

The bacterially purified PKM2 protein or the nuclear lysates (from $5-7 \mathrm{mg} / \mathrm{ml}$ of total protein), was loaded into a Superdex 200 10/300GL column and eluted with elution buffer (50 mM phosphate, $0.15 \mathrm{M} \mathrm{NaCl}, \mathrm{pH} 7.2$ ). Each $300 \mu \mathrm{l}$ consecutive fraction was collected, and $20 \mu \mathrm{l}$ of each fraction was analyzed by immunoblot.

\section{In vitro kinase assay}

Bacterially purified WT and mutants of His-tagged recombinant PKM2 $(10 \mu \mathrm{g} / \mathrm{ml})$ were incubated with GSTtagged H2AX $(10 \mu \mathrm{g} / \mathrm{ml})$ in 50ul kinase buffer (Cell Signaling Technology) at $25^{\circ} \mathrm{C}$ for 2 hours. The reactions were terminated by addition of SDS loading buffer and heated to $100^{\circ} \mathrm{C}$. The reaction mixtures were then analyzed by SDS-PAGE.

\section{Kinetic determination of PKM2 and H2AX interaction}

To determine the kinetic parameters $\left(\mathrm{K}_{\mathrm{m}}\right)$ values for PKM2. The kinase reactions were performed using fixed PKM2 concentration $(0.25 \mu \mathrm{M})$ with varied substrate $(\mathrm{H} 2 \mathrm{AX})$ in the presence of excess PEP at room temperature for $2 \mathrm{~min}$. The reaction mixtures were then analyzed by Western blot. The phosphorylated $\mathrm{H} 2 \mathrm{AX}$ protein bands were quantified by densitometry and the kinetic constants were determined by fitting the data with Michaelis-Menten equation using Graph Pad Prism.

\section{Cell transfection}

For transient transfection, Lipofectamine 2000 transfection reagent was used following the manufacturer's protocol (Invitrogen). Retroviruses were prepared by transient co-transfection with helper plasmids into 293 T cells using Lipofectamine 2000. After the transfection, 1 $\mu \mathrm{g} / \mathrm{ml}$ of puromycin was added to screen stable cell lines for further assays.

\section{Comet assay}

A single-cell gel electrophoresis (comet assay) kit was employed for evaluating DNA damage (Trevigen, Inc.). Etoposide- or UV-treated or untreated MCF7 cells were resuspended in PBS and combined with molten low melting agarose at a ratio of $1: 10(\mathrm{v} / \mathrm{v})$ and immediately pipetted $50 \mu \mathrm{l}$ onto CometSlide. After cell lysis, samples were treated with $\mathrm{NaOH}$ solution $(300 \mathrm{mM} \mathrm{NaOH}, 1 \mathrm{mM}$ EDTA) and applied to electrophoresis. Then the samples were stained with DAPI, and viewed by a fluorescence microscopy [50]. Images were analysed with an ImageJ software plugin Comet Assay from Microscopy Services Laboratory (https://www.med.unc.edu/microscopy) [57]. 


\section{Metaphase spreads and chromosomal aberration analysis}

MCF7 cells (WT or PKM2-depleted) were treated with or without etoposide for 4 hours followed by releasing for 24 hours. The cells were then incubated with Colcemid $(0.2 \mathrm{ug} / \mathrm{ml})$ for 4 hours after which cells were trypsinized and spun down. The cell pellets were resuspended with hypotonic solution $(75 \mathrm{mM} \mathrm{KCl})$ for $10 \mathrm{~min}$ at room temperature, and then fixed by freshly prepared Carnoy solution (3:1 v/v methanol/aceic acid) [58]. Metaphases were hybridized with whole chromosomes 2, 3, 5 fluorescence-labelled DNA probe (XCP, WholeChromosome Probe, MetaSystems) as described in the manual, and were counterstained with DAPI. The slides were viewed with Nikon A1R confocal laser microscope $(100 \times)$. Chromosome aberrations were determined by its structural incomplete, such as translocation, exchange, rearrangement, fragment, or break.

\section{Xenograft tumor assay}

The 6- to 8-week-old female nude mice (Slaccas Laboratory Animal, Shanghai, China) were supplemented with $0.36 \mathrm{mg}$ of 60 -day release $17 \beta$-estradiol pellets (Innovative Research) by subcutaneous inoculation. Then, $1 \times 10^{6}$ MCF7 cells infected with NC or shPKM2\#1 was injected into the left (NC) or right (shPKM2) side of the mammary fat pad of the mice. After 3 weeks, a dose of $0.1 \mathrm{mg} / \mathrm{kg}$ of etoposide or DMSO was administrated intraperitoneally for 7 consecutive days. Two weeks afterwards, the tumors were collected and subjected to western blot analysis.

\section{Statistical analysis}

The Student's t-test was used to compare the difference between two different groups. A value of $\mathrm{p}<0.05$ was considered to be statistically significant.

\section{Author contributions}

L.X., Y.L., and G.-Q.C. designed research; L.X., X.L.W., Y.L., K.Q. and X.-R.W. performed research; L.X., and Y.L. contributed new reagents/analytic tools; L.X., Y.L. and A.-W.Z. analyzed data; and Y.L., and G.-Q.C. wrote the paper.

\section{ACKNOWLEDGMENTS}

We are grateful to Dr Lei Huang for the pGEXH2AX plasmid, and Dr Qunying Lei (Fudan University) for the PKM2-AcK433 antibody.

\section{CONFLICTS OF INTEREST}

All authors concur with this submission and declare no competing financial interests.

\section{FUNDING}

This work was supported by National Key Research Program of China (NO2015CB910403), National Natural Science Foundation (81370652, 81770146, 81230048, $81430061,31570824)$, Foundation for the author of National Excellent Doctoral Dissertation of China (201074), and Talent Development Project of Shanghai Human Resource and Social Security Bureau.

\section{REFERENCES}

1. Christofk HR, Vander Heiden MG, Harris MH, Ramanathan A, Gerszten RE, Wei R, Fleming MD, Schreiber SL, Cantley LC. The M2 splice isoform of pyruvate kinase is important for cancer metabolism and tumour growth. Nature. 2008; 452:230-233.

2. Yang W, Xia Y, Hawke D, Li X, Liang J, Xing D, Aldape K, Hunter T, Alfred Yung WK, Lu Z. PKM2 phosphorylates histone $\mathrm{H} 3$ and promotes gene transcription and tumorigenesis. Cell. 2012; 150:685-696.

3. Vander Heiden MG, Cantley LC, Thompson CB. Understanding the Warburg effect: the metabolic requirements of cell proliferation. Science. 2009; 324:1029-1033.

4. Luo W, Hu H, Chang R, Zhong J, Knabel M, O'Meally R, Cole RN, Pandey A, Semenza GL. Pyruvate kinase M2 is a PHD3-stimulated coactivator for hypoxia-inducible factor 1. Cell. 2011; 145:732-744.

5. Dayton TL, Jacks T, Vander Heiden MG. PKM2, cancer metabolism, and the road ahead. EMBO Rep. 2016; 17:1721-1730.

6. Matsuda S, Adachi J, Ihara M, Tanuma N, Shima H, Kakizuka A, Ikura M, Ikura T, Matsuda T. Nuclear pyruvate kinase M2 complex serves as a transcriptional coactivator of arylhydrocarbon receptor. Nucleic Acids Res. 2016; 44:636-647.

7. Clower CV, Chatterjee D, Wang Z, Cantley LC, Vander Heiden MG, Krainer AR. The alternative splicing repressors hnRNP A1/A2 and PTB influence pyruvate kinase isoform expression and cell metabolism. Proc Natl Acad Sci U S A. 2010; 107:1894-1899.

8. Ikeda Y, Tanaka T, Noguchi T. Conversion of non-allosteric pyruvate kinase isozyme into an allosteric enzyme by a single amino acid substitution. J Biol Chem. 1997; 272:20495-20501

9. Ashizawa K, Willingham MC, Liang CM, Cheng SY. In vivo regulation of monomer-tetramer conversion of pyruvate kinase subtype M2 by glucose is mediated via fructose 1, 6-bisphosphate. J Biol Chem. 1991; 266:16842-16846.

10. Cortes-Cros M, Hemmerlin C, Ferretti S, Zhang J, Gounarides JS, Yin H, Muller A, Haberkorn A, Chene P, Sellers WR, Hofmann F. M2 isoform of pyruvate kinase is dispensable for tumor maintenance and growth. Proc Natl Acad Sci U S A. 2013; 110:489-494. 
11. Noguchi T, Inoue H, Tanaka T. The M1- and M2-type isozymes of rat pyruvate kinase are produced from the same gene by alternative RNA splicing. J Biol Chem. 1986; 261:13807-13812.

12. Vander Heiden MG, Locasale JW, Swanson KD, Sharfi H, Heffron GJ, Amador-Noguez D, Christofk HR, Wagner G, Rabinowitz JD, Asara JM, Cantley LC. Evidence for an alternative glycolytic pathway in rapidly proliferating cells. Science. 2010; 329:1492-1499.

13. Gui DY, Lewis CA, Vander Heiden MG. Allosteric regulation of PKM2 allows cellular adaptation to different physiological states. Sci Signal. 2013; 6:pe7.

14. Wong N, De Melo J, Tang D. PKM2, a central point of regulation in cancer metabolism. Int J Cell Biol. 2013; 2013:242513.

15. Christofk HR, Vander Heiden MG, Wu N, Asara JM, Cantley LC. Pyruvate kinase M2 is a phosphotyrosinebinding protein. Nature. 2008; 452:181-186.

16. Lv L, Li D, Zhao D, Lin R, Chu Y, Zhang H, Zha Z, Liu Y, Li Z, Xu Y, Wang G, Huang Y, Xiong Y, et al. Acetylation targets the M2 isoform of pyruvate kinase for degradation through chaperone-mediated autophagy and promotes tumor growth. Mol Cell. 2011; 42:719-730.

17. Anastasiou D, Poulogiannis G, Asara JM, Boxer MB, Jiang JK, Shen M, Bellinger G, Sasaki AT, Locasale JW, Auld DS, Thomas CJ, Vander Heiden MG, Cantley LC. Inhibition of pyruvate kinase M2 by reactive oxygen species contributes to cellular antioxidant responses. Science. 2011; 334:1278-1283.

18. Hitosugi T, Kang SK, Vander Heiden MG, Chung TW, Elf S, Lythgoe K, Dong SZ, Lonial S, Wang X, Chen GZ, Xie JX, Gu TL, Polakiewicz RD, et al. Tyrosine phosphorylation inhibits PKM2 to promote the Warburg effect and tumor growth. Sci Signal. 2009; 2:ra73.

19. Stetak A, Veress R, Ovadi J, Csermely P, Keri G, Ullrich A. Nuclear translocation of the tumor marker pyruvate kinase M2 induces programmed cell death. Cancer Res. 2007; 67:1602-1608.

20. Spoden GA, Morandell D, Ehehalt D, Fiedler M, JansenDurr P, Hermann M, Zwerschke W. The SUMO-E3 ligase PIAS3 targets pyruvate kinase M2. J Cell Biochem. 2009; 107:293-302.

21. Hoshino A, Hirst JA, Fujii H. Regulation of cell proliferation by interleukin-3-induced nuclear translocation of pyruvate kinase. J Biol Chem. 2007; 282:17706-17711.

22. Wang HJ, Hsieh YJ, Cheng WC, Lin CP, Lin YS, Yang SF, Chen CC, Izumiya Y, Yu JS, Kung HJ, Wang WC. JMJD5 regulates PKM2 nuclear translocation and reprograms HIF1alpha-mediated glucose metabolism. Proc Natl Acad Sci U S A. 2014; 111:279-284.

23. Keller KE, Doctor ZM, Dwyer ZW, Lee YS. SAICAR induces protein kinase activity of PKM2 that is necessary for sustained proliferative signaling of cancer cells. Mol Cell. 2014; 53:700-709.
24. Gao X, Wang H, Yang JJ, Liu X, Liu ZR. Pyruvate kinase M2 regulates gene transcription by acting as a protein kinase. Mol Cell. 2012; 45:598-609.

25. Jiang Y, Li X, Yang W, Hawke DH, Zheng Y, Xia Y, Aldape K, Wei C, Guo F, Chen Y, Lu Z. PKM2 regulates chromosome segregation and mitosis progression of tumor cells. Mol Cell. 2014; 53:75-87.

26. Jiang Y, Wang Y, Wang T, Hawke DH, Zheng Y, Li X, Zhou Q, Majumder S, Bi E, Liu DX, Huang S, Lu Z. PKM2 phosphorylates MLC2 and regulates cytokinesis of tumour cells. Nat Commun. 2014; 5:5566.

27. Xia L, Wang XR, Wang XL, Liu SH, Ding XW, Chen GQ, $\mathrm{Lu}$ Y. A novel role for pyruvate kinase M2 as a corepressor for P53 during the DNA damage response in human tumor cells. J Biol Chem. 2016; 291:26138-26150.

28. Lv L, Xu YP, Zhao D, Li FL, Wang W, Sasaki N, Jiang Y, Zhou X, Li TT, Guan KL, Lei QY, Xiong Y. Mitogenic and oncogenic stimulation of K433 acetylation promotes PKM2 protein kinase activity and nuclear localization. Mol Cell. 2013; 52:340-352.

29. Shimada N, Shinagawa T, Ishii S. Modulation of M2-type pyruvate kinase activity by the cytoplasmic PML tumor suppressor protein. Genes Cells. 2008; 13:245-254.

30. Yang W, Xia Y, Ji H, Zheng Y, Liang J, Huang W, Gao X, Aldape K, Lu Z. Nuclear PKM2 regulates beta-catenin transactivation upon EGFR activation. Nature. 2011; 480:118-122.

31. Ye J, Mancuso A, Tong X, Ward PS, Fan J, Rabinowitz JD, Thompson CB. Pyruvate kinase M2 promotes de novo serine synthesis to sustain mTORC1 activity and cell proliferation. Proc Natl Acad Sci U S A. 2012; 109:6904-6909.

32. Hamabe A, Konno M, Tanuma N, Shima H, Tsunekuni K, Kawamoto K, Nishida N, Koseki J, Mimori K, Gotoh N, Yamamoto H, Doki Y, Mori M, Ishii H. Role of pyruvate kinase M2 in transcriptional regulation leading to epithelialmesenchymal transition. Proc Natl Acad Sci U S A. 2014; 111:15526-15531.

33. Lunt SY, Muralidhar V, Hosios AM, Israelsen WJ, Gui DY, Newhouse L, Ogrodzinski M, Hecht V, Xu K, Acevedo PN, Hollern DP, Bellinger G, Dayton TL, et al. Pyruvate kinase isoform expression alters nucleotide synthesis to impact cell proliferation. Mol Cell. 2015; 57:95-107.

34. Park I, Mukherjee J, Ito M, Chaumeil MM, Jalbert LE, Gaensler K, Ronen SM, Nelson SJ, Pieper RO. Changes in pyruvate metabolism detected by magnetic resonance imaging are linked to DNA damage and serve as a sensor of temozolomide response in glioblastoma cells. Cancer Res. 2014; 74:7115-7124.

35. Lempiainen $\mathrm{H}$, Halazonetis TD. Emerging common themes in regulation of PIKKs and PI3Ks. EMBO J. 2009; 28:3067-3073.

36. Burrows N, Williams J, Telfer BA, Resch J, Valentine HR, Fitzmaurice RJ, Eustace A, Irlam J, Rowling EJ, Hoang-Vu 
C, West CM, Brabant G, Williams KJ. Phosphatidylinositide 3-kinase (PI3K) and PI3K-related kinase (PIKK) activity contributes to radioresistance in thyroid carcinomas. Oncotarget. 2016; 7:63106-63123. https://doi.org/10.18632/ oncotarget. 11056 .

37. Falck J, Coates J, Jackson SP. Conserved modes of recruitment of ATM, ATR and DNA-PKcs to sites of DNA damage. Nature. 2005; 434:605-611.

38. Stewart GS, Wang B, Bignell CR, Taylor AM, Elledge SJ. MDC1 is a mediator of the mammalian DNA damage checkpoint. Nature. 2003; 421:961-966.

39. Stucki M, Clapperton JA, Mohammad D, Yaffe MB, Smerdon SJ, Jackson SP. MDC1 directly binds phosphorylated histone $\mathrm{H} 2 \mathrm{AX}$ to regulate cellular responses to DNA double-strand breaks. Cell. 2005; 123:1213-1226.

40. Oleson BJ, Broniowska KA, Schreiber KH, Tarakanova VL, Corbett JA. Nitric oxide induces ataxia telangiectasia mutated (ATM) protein-dependent gammaH2AX protein formation in pancreatic beta cells. J Biol Chem. 2014; 289:11454-11464.

41. Tanaka T, Huang X, Halicka HD, Zhao H, Traganos F, Albino AP, Dai W, Darzynkiewicz Z. Cytometry of ATM activation and histone $\mathrm{H} 2 \mathrm{AX}$ phosphorylation to estimate extent of DNA damage induced by exogenous agents. Cytometry A. 2007; 71:648-661.

42. Yajima H, Lee KJ, Chen BP. ATR-dependent phosphorylation of DNA-dependent protein kinase catalytic subunit in response to UV-induced replication stress. Mol Cell Biol. 2006; 26:7520-7528.

43. Fernandez-Capetillo O, Chen HT, Celeste A, Ward I, Romanienko PJ, Morales JC, Naka K, Xia Z, CameriniOtero RD, Motoyama N, Carpenter PB, Bonner WM, Chen J, Nussenzweig A. DNA damage-induced G2-M checkpoint activation by histone $\mathrm{H} 2 \mathrm{AX}$ and 53BP1. Nat Cell Biol. 2002; 4:993-997.

44. Fragkos M, Jurvansuu J, Beard P. H2AX is required for cell cycle arrest via the p53/p21 pathway. Mol Cell Biol. 2009; 29:2828-2840.

45. Thiriet C, Hayes JJ. Chromatin in need of a fix: phosphorylation of $\mathrm{H} 2 \mathrm{AX}$ connects chromatin to DNA repair. Mol Cell. 2005; 18:617-622.

46. Chaneton B, Hillmann P, Zheng L, Martin AC, Maddocks OD, Chokkathukalam A, Coyle JE, Jankevics A, Holding FP, Vousden KH, Frezza C, O'Reilly M, Gottlieb E. Serine is a natural ligand and allosteric activator of pyruvate kinase M2. Nature. 2012; 491:458-462.
47. Ashizawa K, McPhie P, Lin KH, Cheng SY. An in vitro novel mechanism of regulating the activity of pyruvate kinase M2 by thyroid hormone and fructose 1, 6-bisphosphate. Biochemistry. 1991; 30:7105-7111.

48. Dombrauckas JD, Santarsiero BD, Mesecar AD. Structural basis for tumor pyruvate kinase M2 allosteric regulation and catalysis. Biochemistry. 2005; 44:9417-9429.

49. Greinert R, Volkmer B, Henning S, Breitbart EW, Greulich KO, Cardoso MC, Rapp A. UVA-induced DNA doublestrand breaks result from the repair of clustered oxidative DNA damages. Nucleic Acids Res. 2012; 40:10263-10273.

50. Wu CC, Liu MT, Chang YT, Fang CY, Chou SP, Liao HW, Kuo KL, Hsu SL, Chen YR, Wang PW, Chen YL, Chuang $\mathrm{HY}$, Lee $\mathrm{CH}$, et al. Epstein-Barr virus DNase (BGLF5) induces genomic instability in human epithelial cells. Nucleic Acids Res. 2010; 38:1932-1949.

51. Bartkova J, Horejsi Z, Koed K, Kramer A, Tort F, Zieger K, Guldberg P, Sehested M, Nesland JM, Lukas C, Orntoft T, Lukas J, Bartek J. DNA damage response as a candidate anti-cancer barrier in early human tumorigenesis. Nature. 2005; 434:864-870.

52. Kastan MB, Bartek J. Cell-cycle checkpoints and cancer. Nature. 2004; 432:316-323.

53. Aguilera A, Garcia-Muse T. Causes of genome instability. Ann Rev Genet. 2013; 47:1-32.

54. Iliakis G, Wang Y, Guan J, Wang H. DNA damage checkpoint control in cells exposed to ionizing radiation. Oncogene. 2003; 22:5834-5847.

55. Yang W, Zheng Y, Xia Y, Ji H, Chen X, Guo F, Lyssiotis CA, Aldape K, Cantley LC, Lu Z. ERK1/2-dependent phosphorylation and nuclear translocation of PKM2 promotes the Warburg effect. Nat Cell Biol. 2012; 14:1295-1304.

56. Lukas J, Lukas C, Bartek J. More than just a focus: the chromatin response to DNA damage and its role in genome integrity maintenance. Nat Cell Biol. 2011; 13:1161-1169.

57. Hirakawa T, Katagiri Y, Ando T, Matsunaga S. DNA doublestrand breaks alter the spatial arrangement of homologous loci in plant cells. Sci Rep. 2015; 5:11058.

58. Savage KI, Gorski JJ, Barros EM, Irwin GW, Manti L, Powell AJ, Pellagatti A, Lukashchuk N, McCance DJ, McCluggage WG, Schettino G, Salto-Tellez M, Boultwood $\mathrm{J}$, et al. Identification of a BRCA1-mRNA splicing complex required for efficient DNA repair and maintenance of genomic stability. Mol Cell. 2014; 54:445-459. 